Article

\title{
Evaluation of the Efficiency of Maritime Transport Using a Network Slacks-Based Measure (SBM) Approach: A Case Study on the Korean Coastal Ferry Market
}

\author{
Joohwan Kim ${ }^{1}\left(\mathbb{D}\right.$ and Hwayoung Kim $^{2, *}$ (i) \\ 1 Transportation Safety Division, Korea Maritime Transportation Safety Authority, Sejong 30100, Korea; \\ kjh710@komsa.or.kr \\ 2 Division of Maritime Transportation, Mokpo National Maritime University, Mokpo 58628, Korea \\ * Correspondence: hwayoung@mmu.ac.kr
}

Citation: Kim, J.; Kim, H. Evaluation of the Efficiency of Maritime Transport Using a Network Slacks-Based Measure (SBM) Approach: A Case Study on the Korean Coastal Ferry Market. Sustainability 2021, 13, 6094. https:// doi.org/10.3390/su13116094

Academic Editor: Christos Kontovas

Received: 19 April 2021

Accepted: 25 May 2021

Published: 28 May 2021

Publisher's Note: MDPI stays neutral with regard to jurisdictional claims in published maps and institutional affiliations.

Copyright: (C) 2021 by the authors. Licensee MDPI, Basel, Switzerland. This article is an open access article distributed under the terms and conditions of the Creative Commons Attribution (CC BY) license (https:/ / creativecommons.org/licenses/by/ $4.0 /)$.

\begin{abstract}
Safety is a key performance indicator for the sustainable management of a coastal ferry service business. An efficiency strategy that balances safety and transport performance should be considered. The purpose of this study is to evaluate the relative transport efficiency of coastal ferry operators through undesirable safety-related output. Coastal ferry operators create added value through logistics activities such as cargo and passenger transport. Accordingly, this study designed a three-stage network-slacks-based measure (SBM) model that delineated production through ferry transport services such as service generation, service execution, and transport value creation. Detention records and marine accidents caused by human errors or technical faults were considered undesirable safety-related outputs. Moreover, the relative transport efficiency of 23 Korean firms that have continuously managed a coastal ferry transport business from 2015 to 2018 was analyzed. The results showed that the differentiation of transport efficiency of firms improved when applying the three-stage network SBM model compared to applying the SBM model that did not consider the internal production stage. This fact suggests that it is more desirable to apply the three-stage network SBM model proposed in this study when a more stringent comparison of transport performance is needed in terms of service quality.
\end{abstract}

Keywords: coastal ferry; transport efficiency; undesirable safety-related output; slacks-based measure of efficiency (SBM); network SBM model

\section{Introduction}

A coastal ferry service provides an effective means of transport for island residents to travel inland when the areas are not connected by a bridge or aviation services are not available. Furthermore, a coastal ferry service can serve as a transport service for tourists visiting an island by connecting it to the mainland. In 2019, there were approximately 14.58 million users of coastal ferry services in Korea, of which 11.03 million (76\%) were general passengers boarding ferries for tourism [1]. Coastal ferry services are also a key part of the logistics, transporting necessary goods to the islands in association with land transportation [2]. As such, coastal ferry services not only guarantee the mobility rights of citizens but also contribute to regional development in alignment with the tourism and logistics business.

In the service industry where production and consumption occur at the same time, such as ferry transport, customer-oriented management is required [3]. It is argued that customers place a priority on the quality of services such as safety, travel time, comfort, and cleanness over fare changes when selecting means of transportation [4]. Especially, safety is considered as a criterion for customers to judge the reliability of transportation service [5]. Therefore, it is regarded as an important indicator representing the quality of service. For example, in the case of the Korean government, the ferry service satisfaction 
survey has been carrying out for the passengers-based on Article 9-the Korean Marine Transportation Act [6]. The survey includes questionnaires regarding the safety level felt by the ferry users, as well as the actual history of safety defects, including marine accidents and last two-year ferry operations. The Korean government has established coastal ferry safety innovative plans in September 2014 in order to prevent marine disasters from safety issues, and it implemented more reinforced ferry safety regulations. In spite of them, there have been at least 44 cases in 2018 and the most 66 cases in 2015 of marine accidents from ferry transportation in the past five years from 2015 to 2019 [7]. Furthermore, it is expected for potential risk against the safety of ferries to increase due to the boost of sea traffic, the expansion of fishing ground, and offshore wind farms in national coastal waters. A single accident can cause mass mortality and property loss because a ferry carries many people and freights at the same time. Consequently, in addition to the government's systematic establishment of an institutional framework on ferry safety, practical safety activities by coastal ferry operators to faithfully implement them are most required. There is a necessity to form a virtuous cycle for the safety activities of a firm to prevent marine accidents and for the reliability of transportation service to improve continuously, creating demands on the ferry service. Therefore, it is reasonable to come up with a strategy pursuing a balance between safety and transport efficiency for sustainable ferry service.

However, studies evaluating efficiency in terms of safety factors in the process of ferry transportation are scarce. This is contrary to the fact that many studies in Korea and overseas have actively employed safety records on accident frequency, number of casualties, and transport performance when measuring transport efficiency scores in other fields of transport services such as railways, roads, and aviation (e.g., Barak and Dahooei [8], Chen et al. [9], Cui and Li [10], Djordjevi et al. [11], Egilmez and McAvoyc [12], Han et al. [13], Pal and Mitra [14], Roets et al. [15], Stolzer et al. [16]). Against this backdrop, this study aims to analyze the overall efficiency of coastal ferry transportation considering service quality represented by safety performance. Meanwhile, customer satisfaction and travel safety perception can be considered to measure safety performance [17]. However, these can only be evaluated after using the transport service, reflecting the subjective propensity [18]. Service quality should be evaluated clearly and concisely so that decision makers and the general public can recognize that level [19]. Therefore, in this study, measurable records of safety defects resulting from safety management failures are taken into account as undesirable output for measuring overall transport efficiency. In other words, this study evaluated whether coastal ferry operators have achieved reasonable production with maximized transport performance and minimized safety defects in sailing compared to other companies while providing an adequate scale of transport services to customers on their licensed routes. With them, it will provide the basis for setting sustainable management goals for a ferry operator to improve customer value in the end while enhancing productivity and quality of transportation service in a balanced manner. A data envelopment analysis (DEA), which is a nonparametric frontier analysis, is applied for the measurement of efficiency. DEA is a method that simultaneously considers the weights of multiple inputs and outputs of decision-making units (DMUs) subject to the efficiency evaluation without presetting, thereby enabling measuring the relative efficiency of DMUs for benchmarking. Considering the characteristics of such undesirable outputs, this study uses the network slack-based measure of efficiency (network SBM) model to evaluate transport efficiency.

The network SBM model used in this study has three advantages that differentiate it from traditional DEA models such as CCR [20] and BCC [21]. First, the network SBM model enables a stricter evaluation because it is based on the SBM model that directly reflects the level of slack improvement of inputs and outputs on efficiency [22,23]. The radial models used in previous studies do not consider nonradial slacks, and thus the efficiency scores are overestimated [24]. Second, undesirable outputs, which are negative variables, can be directly applied to the model without data transformation in an efficiency measurement, thereby maintaining their distinct characteristics. This differs from traditional DEA models that replace the data of undesirable outputs with input factors or 
require data transformation to embrace them as outputs. Third, a more realistic model can be developed by considering the linking activities of each subordinate production stage carried out internally for DMUs to produce final outputs, which can then be considered in an efficiency evaluation [25]. This can overcome the limitations of conventional DEA models that consider the internal linking process hidden in the production process, in which multiple inputs are transformed into final outputs as the black box area and thus not considered [26].

This paper is organized as follows. Section 2 reviews previous studies that analyzed the efficiency of the coastal ferry transport business along with the network DEA model. Section 3 describes the construction of the research model and variables. Section 4 provides the results of evaluating overall transport efficiency based on the safety records of 23 Korean ferry operators from 2015 to 2018 . Section 5 summarizes the results of the study and provides conclusions.

\section{Literature Review}

\subsection{Network DEA}

Various DEA models have been developed since the initial research by Charnes et al. [20]. They can be applied in various ways according to the production type of the subject and characteristics of the given data. Conventional DEA models measure relative efficiency without considering the internal linking activity each DMU undergoes to transform the initial input to final output. Conventional DEA models are based on the assumption that each DMU transforms input into output through the unknown internal production process called the black box. The network DEA model was first proposed to resolve this black box issue $[27,28]$. The overall production process in the network DEA model can be divided into multiple sub-units generally referred to as stages, nodes, and divisions [29]. Intermediates produced as outputs in one unit are reflected again as inputs in another unit that is linked to it. Thus, the network DEA model can measure the divisional efficiency of the interconnected internal production process, and the overall efficiency of DMU is estimated based on the divisional efficiency score. This provides useful information such as what internal activity has caused the inefficiency of DMU, which traditional DEA models considering DMU as the black box are not able to do [28]. Therefore, the network DEA model can provide more meaningful and reliable efficiency analysis results than existing DEA models. With these benefits, the network DEA model has been used to measure operational efficiency in transport and logistics industrial fields such as airlines (e.g., Zhu [30], Lozano and Gutiérrez [31], Zhang et al. [32]), airports (e.g., Lozano et al. [33]), supply chain management (e.g., Chen and Yan [34], Momeni et al. [35], Omrani and Keshavarz [36], Kahi et al. [37]), port (e.g., Wanke [38]), railway (e.g., Yu and Lin [39]), public transit (Hahn et al. [40]), etc.

The initial network DEA model was based on radial models such as CCR and BCC assuming that all inputs or outputs change in proportion [41]. However, it is impossible for all inputs or outputs to change proportionally if inputs are interchangeable when measuring efficiency scores or if there are inputs that cannot be controlled by DMUs. Tone and Tsutsui [25] proposed the network SBM model to overcome the limitations of this initial network DEA model. The network SBM model is based on SBM, a nonradial model proposed by Tone [22]. The SBM model has the characteristic of unit invariance, as it directly reflects the slack improvement ratio of input excess and output shortage in an efficiency measurement. Thus, it can overcome the limitations of radial models [22]. Furthermore, other studies that considered undesirable outputs by expanding the general network SBM include Shirazi and Mohammadi [41], Fukuyama and Weber [42], Huang et al. [43], Lozano et al. [44] and Liu et al. [45]. These studies considered various types of undesirable outputs that meet the characteristics of DMUs such as nonperforming loans of banks, pollutant emissions by businesses, and flight delays, but none reflected undesirable safety-related outputs, which is the aim of this study. In particular, no research has applied network SBM to shipping companies considering undesirable safety-related outputs. 


\subsection{DEA Application Studies in Ferry Transport}

DEA, the theoretical foundation of this study, is a method by which to empirically measure an organization's relative efficiency. It has recently been applied to marine logistics. Since Førsund [46], studies that measure the efficiency of the marine transport business have been conducted with a focus on overseas freight transportation services (e.g., Bang et al. [47], Chao at al. [48], Chung and Hwang [49], Gong et al. [50], Gutiérrez et al. [51], Huang et al. [52], Lin et al. [53], Panayides et al. [54]). Compared to the freight business, fewer studies have analyzed the efficiency of the coastal ferry transport business using DEA. Førsund [46] evaluated parametric efficiency under the deterministic frontier based on the Cobb-Douglas production function of 23 coastal ferry operators in Norway, and comparatively analyzed the nonparametric efficiency scores measured through the DEA model. Chang [55] measured the operational efficiency of 50 coastal passenger routes in Korea using traditional DEA models such as CCR and BCC. Like Chang [55], Jo and Yeo [56] also evaluated operational efficiency using the CCR and BCC models, focusing on passenger routes in Korea. They used the same method as Chang [55] in selecting variables for efficiency measurement. However, their study differs from Chang [55] in that they investigated the change in ferry transport productivity of 14 routes from 2007 to 2012 using the Malmquist productivity index of Caves et al. [57]. Yu et al. [58] used DEA models in a performance analysis to efficiently allocate government subsidies to coastal ferry operators in Taiwan. To estimate the subsidy allocation ratios of seven coastal ferry operators in Taiwan, Yu et al. [58] measured the operational efficiency of the operators by applying a mixed model that adopted the concept of cross-efficiency proposed by Du et al. [59] in the DEA. Unlike the aforementioned studies, Park et al. [60] observed changes in coastal ferry transport efficiency in each area of Korea from 2007 to 2016 by applying both the SBM model [22] and DEA-window model [61]. In so doing, they identified a clear change in the operational efficiency of the ferry transport business in Korea before and after the Sewol ferry disaster (2014). Pham et al. [62] analyzed the operational efficiency of 25 general routes and 13 subsidized service routes established in Mokpo, Korea using the CCR and BCC models. Their study considered passenger travel constraints (sailing time, sailing distance, and travel distance to ticket office and boarding gate), which may affect the quality of transport service, as input variables. They performed a principal component analysis (PCA) to simplify the dataset of various input factors related to passenger travel constraints such as service availability, service adaptability, and service accessibility, and applied the transformed input variables. Park and Yeo [63] evaluated the ferry transport efficiency of 10 competent offices with jurisdiction by dividing coastal ferry routes in Korea into 9 regional administrations and 1 conservancy. Unlike the aforementioned studies that considered only desirable outputs, their study also considered sailing cancellation rate as an undesirable output alongside desirable outputs. Moreover, they compared the efficiency scores of employing and not employing undesirable outputs as variables and then analyzed the effect of undesirable outputs on ferry transport efficiency. The results of their analysis showed that the transport efficiency scores were generally low when the number of canceled days was considered an undesirable output. However, because sailing is determined by the marine weather conditions that day, it cannot be assumed that the number of sailing cancellations represents the ferry operator's level of safety. Besides, there is a difference from this study in that they did not consider the internal linking activity in the transport service production stage by applying the general SBM model in the transport efficiency measurement. Other studies, which focus on different subjects, include Chang et al. [64], who analyzed the economic operational efficiency of cruise lines using the network SBM model. However, the expected undesirable outputs are not considered in the study. Only profitability indicators, such as passenger ticket revenue, onboard and other revenue, and net income were selected as the outputs when analyzing operational efficiency.

The literature review indicates that this study can contribute to the existing body of knowledge based on the following aspects that differentiate it from other research. 
First, this study provides the results of coastal ferry transport efficiency measurement considering undesirable safety-related outputs. They have not yet been considered despite their importance in the previous DEA application studies in ferry transport service. Second, this study delineates the internal linking process through the overall coastal ferry service production and presents more comprehensive transport efficiency scores using the network SBM model. Because there is no case of applying the network SBM model to coastal ferry service, the discrimination of network efficiency scores can be demonstrated by comparing them with the efficiency scores measured through the conventional DEA model.

\section{Method}

\subsection{Design of Network SBM Model}

Coastal ferry operators create added value by carrying goods and passengers. It is assumed that undesirable safety-related outputs are produced alongside desirable outputs in the production stage of transport service activities. To create this production environment, this study designed a transport efficiency measurement model based on the SBM model by Tone [23] and the network model by Huang et al. [43] that reflects undesirable outputs.

In order to realize network SBM model, the internal linking activities are configured in the following three categories for the production of transportation service on coastal ferry operators. The first stage is the service generation stage (hereafter referred to as "SG"). In the SG stage, ferry operators decide the scale of transport service to be provided to customers including the number of ferries to be mobilized and travel schedules on each route in consideration of annual transport volume targeted by them. Second stage is the service execution stage (hereinafter referred to as "SE"). In the SE stage, ferry operators provide transport service generated in the SG stage to customers and actually transport passengers and goods. Lastly, the third stage is the transport value creation stage (hereafter referred to as "TV"). In the TV stage, ferry operators create economic value they desire based on the performance of transportation in the SG stage. The undesirable safety-related outputs reflected in this study can be described as negative values created in the final process in which coastal ferry operators create transport value. They are unwanted products that must be reduced in the transport process. To enhance transport value, it is necessary to improve transport performance and reduce the undesirable safety-related outputs that inhibit transport sustainability. Figure 1 shows a diagram of the network structure for coastal ferry transport services designed in this study.

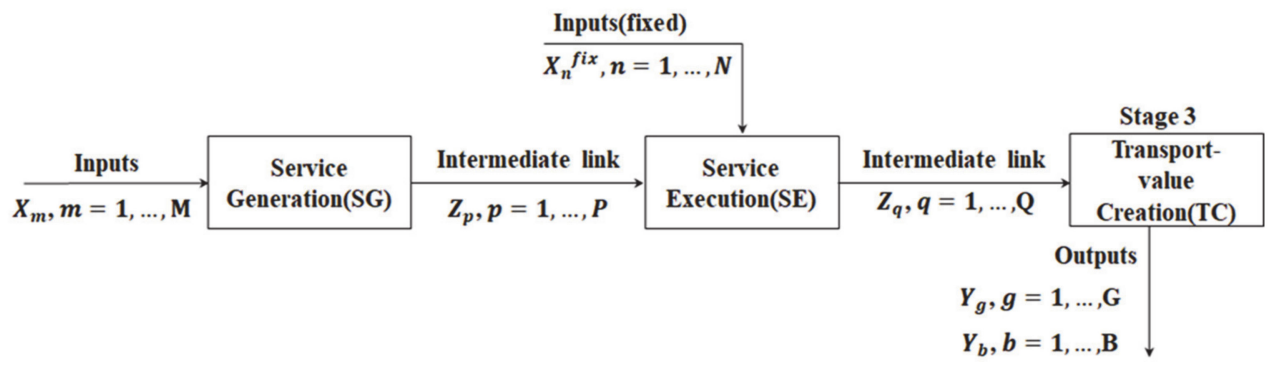

Figure 1. Network production for coastal ferry transport service.

As Figure 1 shows, $\operatorname{DMU}_{j}(j=1, \cdots, J)$ calculates $P$ types of intermediate $Z_{p j}$ $(p=1, \cdots, \mathrm{P})$ using $\mathrm{M}$ types of input $X_{m j}(m=1, \cdots, \mathrm{M})$ in the SG stage. In the SE stage, it is assumed that $\mathrm{Q}$ types of intermediate $Z_{q j}(q=1, \cdots, Q)$ are calculated using intermediate $Z_{p}$ and $\mathrm{N}$ types of fixed input $X_{n j}^{f i x}(n=1, \cdots, \mathrm{N})$. In the final TC stage, intermediate $Z_{q}$ is assumed to calculate $G$ types of desirable output $Y_{g j}(g=1, \cdots, G)$ and B types of undesirable output $Y_{b j}(b=1, \cdots, B)$. 
The variable returns to scale (VRS) can be assumed under this network (SG $\rightarrow \mathrm{SE} \rightarrow \mathrm{TC}$ ) structure to summarize the network SBM model for the transport efficiency measurement of $\mathrm{DMU}_{o}$, as shown in Equation (1).

$$
\begin{gathered}
\min _{\theta^{N}, s_{m}^{-}, s_{g}^{+}, s_{b}^{-}, \lambda_{j}^{S G}, \lambda_{j}^{S E}, \lambda_{j}^{T C}} \theta_{o}^{N}\left(X_{m}, Z_{p}, X_{n}^{f i x}, Z_{q}, Y_{g}, Y_{b}\right) \\
=\min \frac{1-\frac{1}{M} \sum_{m=1}^{M} \frac{s_{m}^{-}}{X_{m o}}}{1+\frac{1}{G+B}\left(\sum_{g=1}^{G} \frac{s_{g}^{+}}{Y_{g o}}+\sum_{b=1}^{B} \frac{s_{b}^{-}}{r_{b o}}\right)}
\end{gathered}
$$

Subject to

$$
\begin{gathered}
\sum_{j=1}^{J} \lambda_{j}^{S G} X_{m j}+s_{m}^{-}=X_{m o}, \forall m \\
\sum_{j=1}^{J} \lambda_{j}^{S G} Z_{p j}=\sum_{j=1}^{J} \lambda_{j}^{S E} Z_{p j}, \forall p \\
\sum_{j=1}^{J} \lambda_{j}^{S E} X_{n j}^{f i x}=X_{n o}^{f i x}, \forall n \\
\sum_{j=1}^{J} \lambda_{j}^{S E} Z_{q j}=\sum_{j=1}^{J} \lambda_{j}^{T V} Z_{q j}, \forall q \\
\sum_{j=1}^{J} \lambda_{j}^{T C} Y_{g j}-s_{g}^{+}=Y_{g o}, \forall g \\
\sum_{j=1}^{J} \lambda_{j}^{T C} Y_{b j}-s_{b}^{-}=Y_{b o}, \forall b \\
\lambda_{j}^{S G}+\lambda_{j}^{S E}+\lambda_{j}^{T C}=1, \lambda_{j}^{S G}, \lambda_{j}^{S E}, \lambda_{j}^{T C} \geq 0, \forall j \\
s_{m}^{-}, s_{g}^{+}, s_{b}^{-} \geq 0, \forall m, g, b
\end{gathered}
$$

where $\lambda_{j}^{S G}, \lambda_{j}^{S E}, \lambda_{j}^{T C}$ represent the intensity vectors in the SG, SE, and TC stages, and $s_{m}^{-}(m=1, \cdots, \mathrm{M}), s_{g}^{+}(g=1, \cdots, G), s_{b}^{-}(b=1, \cdots, B)$ represent the slacks vectors of input, desirable output, and undesirable output, respectively. The objective function $\left(\theta^{N}\right)$ of the network SBM model deals with only initial input excess, desirable output shortage, and undesirable output excess, and does not directly consider intermediate excess and shortage in the objective function. Instead, the intermediate is correlated with the transport efficiency scores by the constraint Equations (3) and (5), which indicate the network link. Fixed input in the SE stage is a variable that cannot be eliminated freely by the DMU; thus, slacks to improve transport efficiency are not considered. The value of the objective function $\left(\theta^{N}\right)$ represents the transport efficiency score, with 1 indicating that all stages of SG, SE, and TC are efficient, and thus that the DMU has transport efficiency. On the other hand, if the value of the objective function $\left(\theta^{N}\right)$ is not 1 , inefficiency is indicated in all or part of the stages of SG, SE, and TC, demonstrating that the DMU is ultimately not efficient. Furthermore, the closer the value is to 0 , the higher the inefficiency. Finally, the divisional efficiency of SG, SE, and TC is measured as shown in Equations (10)-(12).

$$
\begin{gathered}
\theta_{o}^{S G}=1-\frac{1}{M} \sum_{m=1}^{M} \frac{s_{m}^{-*}}{X_{m o}} \\
\theta_{o}^{S E}=\frac{1-\frac{1}{P+N} \sum_{p=1}^{P} \frac{s_{p}^{-*}}{Z_{p o}}}{1+\frac{1}{Q} \sum_{q=1}^{Q} \frac{s_{q}^{+*}}{Z_{q o}}}
\end{gathered}
$$




$$
\theta_{o}^{T C}=\frac{1}{1+\frac{1}{G+B}\left(\sum_{g=1}^{G} \frac{s_{g}^{+*}}{Y_{g o}}+\sum_{b=1}^{B} \frac{s_{b}^{-*}}{Y_{b o}}\right)}
$$

where, $s_{m}^{-*}$ represents optimal slacks of input in the SG stage, $s_{p}^{-*}$ represents optimal slacks in the SE stage, $s_{q}^{-*}\left(s_{q}^{+*}\right)$ represents optimal slacks of output (TC stage input) in the SE stage, and $s_{g}^{+*}, s_{b}^{-*}$ represents optimal slacks of desirable output and undesirable output in the TC stage.

\subsection{Selection of Variables}

The DEA model has the advantage of simultaneously considering multiple variables in the efficiency measurement. However, the efficiency score may be distorted when similar variables are selected redundantly. Thus, transport efficiency must be evaluated by selecting an adequate number of variables that meet the purpose of the study. To this end, this study reviewed the key variables adopted in the previous literature reviewed in Section 2.2. Among many variables, ferry service characteristics were considered to integrate variables with mutually similar meanings into one variable. Moreover, the reliability of the research is increased by selecting substitution variables when there are more realistic variables than those employed in previous studies. Table 1 shows the input-output-intermediate variables ultimately selected for the purposes of this study.

Table 2 shows the method used to measure each variable.

Table 1. Variables for measuring transport efficiency.

\begin{tabular}{cccc}
\hline Inputs & Intermediates & Desirable Output & Undesirable Output \\
\hline$X_{1}:$ Fleet size & $Z_{1}:$ Transport capacity & $Y^{g}:$ Revenue & $Y^{b}:$ Safety defects records \\
$X_{2}:$ Service frequency & $Z_{2}:$ Passenger-km & & \\
$X^{f i x}:$ Route distance & & \\
\hline
\end{tabular}

Table 2. Description of variables for measuring transport efficiency.

\begin{tabular}{cc}
\hline Var. & Description \\
\hline$X_{1}$ & The number of ships actually operated during the observation period (Except for the reserve fleet owned by ferry operators) \\
$X_{2}$ & The number of available service frequencies during the observation period \\
$X^{f i x}$ & Sum of the Origin-Destination distance of ferry operators' licensed routes \\
$Z_{1}$ & Sum of the allowable number of passengers on board the ships \\
$Z_{2}$ & Total number of carried passengers multiplied to the distance travelled during the observation period \\
$Y^{g}$ & Total revenue from ferry transport service during the observation period \\
$Y^{b}$ & Total number of accident and detention records during the observation period \\
\hline
\end{tabular}

First, input variables in the SG stage such as "Fleet size" $\left(X_{1}\right)$ and "Service frequency" $\left(X_{2}\right)$ were measured by the number of ships actually operated and number of available service frequencies on each route. "Transport capacity" $\left(Z_{1}\right)$, which is the intermediate calculated in the SG stage by including these variables, was measured by the sum of transport capacity of the ferry used in each voyage. The number of ships actually operated is considered in studies by Park et al. [60] and Park and Yeo [63], and this is the most fundamental input to start a ferry transport service. In addition, the number of available service frequencies on the route can represent the transport service frequency provided by the company for customers. The more available service frequencies there are, the more ferry transport opportunities they possess compared to other operators. Thus, this variable determines the number of passengers that can be accommodated by the ship.

"Route distance" was selected as the fixed input variable $\left(X^{f i x}\right)$ in the SE stage. According to Article 4 of the Korean Marine Transportation Act, coastal ferry operators must operate only permitted routes; thus, "route distance" was also selected as an input by Chang [55], Jo and Yeo [56], and Pham et al. [62]. "Route distance" is a key factor determining the fare of the company and represents the ship's exposure to marine risks. Thus, this variable is also related to ship safety. However, route distance is not a variable that can be 
adjusted by coastal ferry operators at their discretion. As such, it is used as a fixed input variable in the SE stage. "Route distance" is included with "Transport capacity" $\left(Z_{1}\right)$, the intermediate in the SG stage, to calculate another intermediate, namely "Passenger-km" $\left(Z_{2}\right)$ in the SE stage. "Passenger-km" is measured by multiplying the number of passengers carried on each route by distance traveled by the ship.

"Revenue" represents the profitability of the business operator. It was selected as a desirable output variable $\left(Y^{g}\right)$ the company aims to ultimately generate in the TC stage. Chang et al. [64] and Yu et al. [58] also considered the revenue an output. Furthermore, safety defects records (hereafter "SDR") were selected as an undesirable safety-related output $\left(Y^{b}\right)$. Safety defects are undesirable outputs from the decreasing safety level of the company. However, this has not been used as an output variable thus far in previous studies on the efficiency of the coastal ferry transport business. Therefore, this study measures the SDR of coastal ferry operators based on Equation (13). In this study, SDR is defined as the sum of the accident records (hereafter "AR") of accidents due to human errors or technical faults in the ship operated by the business operator and detention records (hereafter "DR") according to the legal safety inspection causing delays of the ship's voyage. However, for marine accidents, a qualitative gap is perceived by coastal ferry operators in safety management performance depending on the magnitude of the ship's damage or number of casualties. Adding up all marine accidents that occurred without considering the magnitude of the damage due to marine accidents is inadequate as an index to compare the safety level of companies. Thus, for AR, the weights of the type of damage from marine accidents are reflected as shown in Equation (14), after which the performance that is converted based on minor accidents (no damage + no casualties) with the lowest level of damage from accidents is applied.

$$
\begin{gathered}
S D R_{j}=\sum_{l=1}^{L} A R_{j k}^{l}+\sum_{m=1}^{M} D R_{j k}^{m} \\
A R^{l}=\frac{D_{o}^{l} \times w_{o}+C_{p}^{l} \times w_{p}}{N D \times w_{N D}+N C \times w_{N C}}
\end{gathered}
$$

$j$ : $j$ th coastal ferry operators $(j=1, \cdots, \mathrm{J})$;

$k$ : $k$ th ship in operation $(k=1, \cdots, \mathrm{K})$;

$l$ : $l$ th marine accidents $(l=1, \cdots, \mathrm{L})$;

$m$ : $m$ th legal safety inspection $(m=1, \cdots, \mathbf{M})$;

$D_{o}: o$ types of ship damage ( $o=$ total loss, significant damage, minor damage, no damage);

$C_{p}: p$ types of casualties ( $p=1$ st class, 2 nd class, 3 rd class casualties);

$w_{0}$ : Weight factor by ship damage type;

$w_{p}$ : Weight factor by casualty type;

ND: No damage;

NC: No casualties.

Weights by ship damage type $\left(w_{0}\right)$ and weights by casualty type $\left(w_{p}\right)$ considered in Equation (14) apply the results of the study by Kim et al. [65] conducted by the author, as shown in Table 3.

One thing to note is that the measurement criteria of the SDR are designed based on the maritime safety standards of Korea. Therefore, it may be challenging to apply the above measures if the DMUs are ferry operators from other countries. However, both maritime accident and detention records reflected in the SDR are clear and concise indicators that can be commonly considered safety management performance in any country. Additionally, if the variables for undesirable safety-related output are not measurable or acceptable, they can only be removed from the network SBM model to measure transport efficiency from an economic perspective. The model can be flexibly transformed by constructing input and output variables with management-related or service-quality-related parameters. 
Table 3. Relative weights of types of damage from marine accidents.

\begin{tabular}{ccc}
\hline Classification & Damage Type & Weight $(\mathbf{w})$ \\
\hline \multirow{3}{*}{ Ship damage } & Total loss & 0.238 \\
& Significant damage & 0.092 \\
& Minor damage & 0.030 \\
& No damage & 0.019 \\
\hline \multirow{2}{*}{ Casualties } & 1st class casualties & 0.410 \\
& 2nd class casualties & 0.145 \\
& 3rd class casualties & 0.048 \\
\hline
\end{tabular}

Source: Kim et al. [65].

\subsection{Data Description}

It is desirable to have a greater number of samples for analysis when applying the network SBM model, and the number of necessary samples is closely related to the number of inputs and outputs. This study selected 23 firms that continued to operate a coastal ferry transport business for 4 years (2015-2018) of the 59 companies (100 routes, 162 vessels) with a license to operate a coastal ferry transport business in 2019. Considering previous theories [66,67] about the number of observed values, 23 DMUs are more than two times (number of inputs $\times$ number of outputs) the values; thus, there is no problem in the number of observed values. The analysis data were constructed based on 73 general routes for which each coastal ferry operator obtained permission from the government. Statistical data provided by the Korea Maritime Safety Tribunal were used to determine the types of marine accidents experienced by each coastal ferry operator, ship damage due to marine accidents, and the number of casualties and injuries. To ensure an equal comparison of safety performance between companies, uncontrollable marine accidents such as those related to entanglement, which cannot be prevented in advance through voluntary safety management efforts, were excluded from the performance analysis when collecting marine accident data. Units are irrelevant in a network SBM model; thus, the data were normalized by the mean of each variable $\left(\frac{a_{i j}}{\sum_{j=1}^{J} a_{i j} / J}\right)$, and applied to the model. Table 4 summarizes the descriptive statistics of the normalized data of each variable observed for 23 DMUs.

Table 4. Descriptive statistics of the variables.

\begin{tabular}{cccccccc}
\hline Var. & $\boldsymbol{X}_{1}$ & $\boldsymbol{X}_{2}$ & $\boldsymbol{X}^{\text {fix }}$ & $\boldsymbol{Z}_{1}$ & $\boldsymbol{Z}_{2}$ & $\boldsymbol{Y}^{\boldsymbol{g}}$ & $\boldsymbol{Y}^{b}$ \\
\hline Mean & 1.000 & 1.000 & 1.000 & 1.000 & 1.000 & 1.000 & 1.000 \\
Std Dev. & 0.430 & 0.712 & 1.123 & 0.920 & 1.616 & 1.569 & 0.973 \\
Max. & 0.450 & 0.507 & 1.262 & 0.847 & 2.612 & 2.461 & 0.947 \\
Min. & 0.185 & 0.145 & 0.091 & 0.181 & 0.034 & 0.056 & 0.000 \\
\hline
\end{tabular}

To obtain meaningful results, the data set used in the DEA method should be isotonic. In other words, the level of output should be at least the same, or not decrease when inputs increase during the production process [68]. Pearson correlation matrix was constructed to examine whether the collected data meet the isotonicity criteria. The variables in each stage showed positive correlations at a significance level of $1 \%, 5 \%$ as shown in Table 5 .

In addition, it was assumed that the data set for inputs and outputs in the network SBM model have measurable positive values. When performing empirical analysis, however, various forms of data, such as zero value and negative value, can be observed. Furthermore, data may be given in the form of categories or ranking rather than exact values. In this case, it may not be possible to apply such imprecise data to the network SBM model, or the results may be difficult to understand even if they are applied. The data set used in this study was neither ranked by the nature of the variables nor given interval values, and it doesn't have a negative value. However, there is no record of marine accidents or detentions during the observation period (2015-2018) so that the undesirable output can 
have a value of zero. In this case, we considered the method proposed by Yeh [69] for replacing the small positive value (i.e., $10^{-6}$ ) instead of zero while mitigating the effects on the efficiency analysis.

Table 5. Correlation coefficients of the variables in SG, SE, TC stages.

\begin{tabular}{|c|c|c|c|c|}
\hline Stage & Var. & $X_{1}$ & $X_{2}$ & $Z_{1}$ \\
\hline \multirow{3}{*}{ SG } & $X_{1}$ & 1.000 & & \\
\hline & $X_{2}$ & 0.269 & 1.000 & \\
\hline & $Z_{1}$ & $0.491 *$ & $0.448 *$ & 1.000 \\
\hline \multirow{4}{*}{ SE } & Var. & $Z_{1}$ & $X^{f i x}$ & $Z_{2}$ \\
\hline & $Z_{1}$ & 1.000 & & \\
\hline & $X^{f i x}$ & 0.031 & 1.000 & \\
\hline & $Z_{2}$ & 0.057 & $0.752^{* *}$ & 1.000 \\
\hline \multirow{4}{*}{$\mathrm{TC}$} & Var. & $Z_{2}$ & 18 & $y^{b}$ \\
\hline & $Z_{2}$ & 1.000 & & \\
\hline & $Y^{g}$ & $0.970^{* *}$ & 1.000 & \\
\hline & $Y^{b}$ & $0.727 * *$ & $0.656^{* *}$ & 1.000 \\
\hline
\end{tabular}

\section{Results and Discussion}

Transport efficiency was measured using the normalized data of input/output variables summarized for each of the 23 firms during the same period. There is a gap in the size of firms operating a ferry transport business in Korea. Thus, the efficiency analysis was conducted with the assumption of non-oriented VRS considering both input and output efficiencies.

Table 6 provides the results of comparing the transport efficiency analysis of the threestage network SBM model in this study and the SBM model, which considered the internal production stage as a black box. For equal comparison, both models reflected undesirable safety-related outputs as final outputs of transport service.

The results of the transport efficiency analysis using the network SBM model show that one DMU was efficient (DMU 8), scoring 1 in overall efficiency. Four DMUs (DMU 11, $14,17,18$ ) had relatively high overall efficiency scores (higher than 0.700 ), although this is not considered efficient. The mean of the overall efficiency scores of 23 DMUs was 0.459 . A comparison of the divisional efficiency analysis results of SG, SE, and TC shows that the average efficiency score in SG was $0.534,0.600$ in SE, and 0.582 in TC. As such, the score was slightly higher in the SE stage, although this did not differ much. However, comparing the number of DMUs that are efficient, there was a relatively large difference: two DMUs in SG (DMU 8, 20), eight DMUs in SE (DMU 2, 8, 5, 6, 13, 18, 21, 20), and five DMUs in TC (DMU 8, 11, 14, 17, 18, 21). This shows an excessive input slacks in terms of the fleet size even though the coastal ferry operators stably implement scheduled transport service. The reason why the number of DMUs in strong efficiency decreases in the SG stage that represents input-oriented efficiency is found from business characteristic of coastal ferry transportation. Coastal ferries are classified as a public transit according to the Article 2 from Korean Act on the Support and Promotion of Utilization of Public Transit System. In other words, coastal ferry contains characteristics of public service to pursue public interest as the one and only transportation means connecting island areas. Therefore, coastal ferry operators need to reinforce safety and secure convenient facilities for passengers based on the Article 4, Korean Marine Transportation Act, while following travel schedules officially reported to the government except for unavoidable cancellation by weather conditions and etc. There is a need to accept the fact that inputs such as operating vessels or sailing frequency have been excessively utilized due to political causes including the guarantee of rights for mobility of citizens. 
Table 6. Transport efficiency score measured by SBM and Network SBM.

\begin{tabular}{|c|c|c|c|c|c|c|c|c|}
\hline \multirow{3}{*}{ DMU } & \multirow{3}{*}{ SBM } & \multicolumn{7}{|c|}{ Network SBM } \\
\hline & & \multirow{2}{*}{ Overall Efficiency } & \multicolumn{3}{|c|}{ Divisional Efficiency } & \multicolumn{3}{|c|}{ Reference Set $(\lambda)$} \\
\hline & & & SG & SE & TC & SC & SE & TV \\
\hline 2 & 1.000 & 0.273 & 0.579 & 1.000 & 0.346 & $4(0.050) ; 20(0.950)$ & $2(1.000)$ & $8(0.320) ; 12(0.680)$ \\
\hline 3 & 0.167 & 0.127 & 0.343 & 0.110 & 0.190 & $4(0.040) ; 20(0.960)$ & $2(0.346) ; 8(0.569) ; 18(0.085)$ & $11(0.098) ; 12(0.902)$ \\
\hline 4 & 0.295 & 0.257 & 0.350 & 0.086 & 0.380 & $4(0.163) ; 20(0.837)$ & $2(0.605) ; 18(0.395)$ & 11(0.547); 12(0.453) \\
\hline 5 & 1.000 & 0.592 & 0.843 & 1.000 & 0.643 & $4(0.049) ; 20(0.951)$ & $5(1.000)$ & 11(0.801); 17(0.199) \\
\hline 7 & 1.000 & 0.324 & 0.719 & 0.456 & 0.377 & $4(0.040) ; 20(0.960)$ & 2(0.553); 8(0.399); 18(0.0478) & $11(0.048) ; 12(0.952)$ \\
\hline 8 & 1.000 & 1.000 & 1.000 & 1.000 & 1.000 & $8(1.000)$ & $8(1.000)$ & $8(1.000)$ \\
\hline 9 & 0.527 & 0.398 & 0.315 & 0.830 & 0.605 & $4(0.148) ; 20(0.852)$ & $6(0.964) ; 18(0.036)$ & $11(0.078) ; 12(0.923)$ \\
\hline 10 & 0.616 & 0.225 & 0.620 & 0.168 & 0.277 & $4(0.018) ; 20(0.982)$ & $5(0.006) ; 8(0.916) ; 18(0.079)$ & $11(0.085) ; 12(0.858) ; 17(0.057)$ \\
\hline 11 & 1.000 & 0.708 & 0.417 & 0.844 & 1.000 & $4(0.185) ; 20(0.815)$ & $5(0.381) ; 8(0.121) ; 18(0.500)$ & $11(1.000)$ \\
\hline 12 & 0.420 & 0.395 & 0.268 & 0.159 & 0.623 & $4(0.154) ; 20(0.846)$ & 6(0.931); 18(0.069) & $11(0.114) ; 17(0.886)$ \\
\hline 13 & 1.000 & 0.398 & 0.365 & 1.000 & 0.583 & $4(0.168) ; 20(0.8325)$ & $13(1.000)$ & $11(0.614) ; 17(0.386)$ \\
\hline 14 & 1.000 & 0.817 & 0.634 & 0.793 & 1.000 & $20(1.000)$ & $4(0.006) ; 5(0.045) ; 8(0.874) ; 20(0.075)$ & $14(1.000)$ \\
\hline 15 & 0.705 & 0.384 & 0.401 & 0.798 & 0.548 & $4(0.067) ; 20(0.933)$ & $2(0.841) ; 6(0.149) ; 18(0.010)$ & $11(0.009) ; 12(0.991)$ \\
\hline 17 & 1.000 & 0.771 & 0.543 & 0.673 & 1.000 & $4(0.089) ; 20(0.911)$ & $2(0.579) ; 6(0.419) ; 18(0.003)$ & $17(1.000)$ \\
\hline 18 & 1.000 & 0.887 & 0.775 & 1.000 & 1.000 & $4(0.335) ; 20(0.665)$ & $18(1.000)$ & $18(1.000)$ \\
\hline 19 & 0.235 & 0.195 & 0.373 & 0.084 & 0.284 & $4(0.176) ; 20(0.824)$ & $6(0.818) ; 18(0.182)$ & $11(0.278) ; 12(0.722)$ \\
\hline 20 & 1.000 & 0.617 & 1.000 & 1.000 & 0.617 & $20(1.000)$ & $20(1.000)$ & $11(0.314) ; 17(0.686)$ \\
\hline 21 & 1.000 & 0.618 & 0.687 & 1.000 & 0.732 & $4(0.468) ; 20(0.532)$ & $21(1.000)$ & 11(0.099); 17(0.901) \\
\hline 22 & 0.226 & 0.168 & 0.321 & 0.159 & 0.255 & $4(0.081) ; 20(0.919)$ & $2(0.575) ; 8(0.261) ; 18(0.164)$ & 11(0.208); 17(0.792) \\
\hline 23 & 0.374 & 0.235 & 0.213 & 0.148 & 0.388 & $4(0.007) ; 20(0.993)$ & $5(0.263) ; 8(0.539) ; 20(0.198)$ & $11(0.250) ; 17(0.750)$ \\
\hline Avg. & 0.724 & 0.459 & 0.534 & 0.600 & 0.582 & & & \\
\hline
\end{tabular}


In addition, 12 DMUs (DMU 2, 5, 6, 7, 8, 11, 13, 14, 17, 18, 20, 21) had an efficiency score of 1.000 in the general SBM model, more than in the network SBM model. Moreover, the average transport efficiency score of 23 DMUs was 0.724 , about 1.6 times higher than that in the network SBM model. The general SBM model lacked differentiation in relative transport efficiency compared to the analysis results of the three-stage network SBM model.

Table 7 provides the results of the correlation analysis between overall efficiency and divisional efficiency scores in the SG, SE, and TC stages in the network SBM model. All three stages demonstrated a strong positive correlation with overall efficiency, with a correlation coefficient higher than 0.6. Especially, there is a need to pay attention to how overall efficiency is the most correlated with the score of divisional efficiency in the TC stage. About $82 \%$ of coastal ferry routes in Korea are exclusively managed in the monopolized form for a single firm operating on a single route except for a few competing routes such as Mokpo-Hongdo or Pohang-Ulleung. Therefore, the competition in the service between coastal ferry operators is not fierce. In addition, passenger demand is relatively stable unless there are rapid external changes in the environment such as current the pandemic under COVID-19. Therefore, according to the results of previous studies dealing with operating efficiency in the coastal ferry route, efficiency has been determined mostly by the inefficiency of inputs such as the fleet size or sailing frequency $[50,51,58]$. In contrast, the results of efficiency evaluation in this study show how overall efficiency of transportation has been mostly determined by the output rather than input efficiency. In other words, this implies, by reflecting the negative values of undesirable safety-related outputs, that it was possible to conduct a more balanced evaluation of the transport performance of coastal ferry operators in terms of service quality, rather than lean toward the provision of economic transport.

Table 7. Correlation coefficients of the overall efficiency and divisional efficiency scores.

\begin{tabular}{llccc}
\hline \multirow{2}{*}{ Classification } & & \multicolumn{3}{c}{ Divisional Efficiency } \\
\cline { 3 - 5 } & & $\boldsymbol{\theta}^{S G}$ & $\boldsymbol{\theta}^{S E}$ & $\boldsymbol{\theta}^{\text {TC }}$ \\
\hline Overall efficiency & $\theta^{N}$ & $0.649^{* *}$ & $0.699^{* *}$ & $0.960^{* *}$ \\
\hline$* 0<0.01$. & & &
\end{tabular}

Figure 2 is a graph of the transport efficiency scores of the DMUs measured using the three-stage network SBM model and general SBM model in light of undesirable safetyrelated outputs.

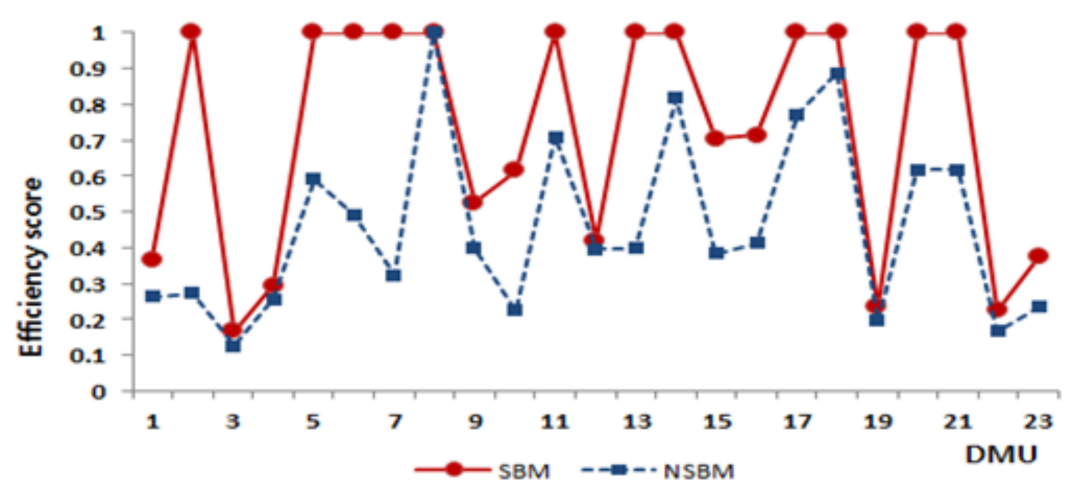

Figure 2. Comparison of efficiency scores between SBM and Network SBM with undesirable safetyrelated output.

As Figure 2 shows, the transport efficiency scores in the network SBM model were either lower than or equivalent to the general SBM model. Moreover, compared to the general SBM model, the number of efficient DMUs tended to decrease in the network SBM model. Even if the DMU is considered efficient in the general SBM model, it may become 
inefficient in the network SBM model. This shows the limitation in applying the general SBM model, which fails to analyze the cause of inefficiency in the internal production stage by overestimating transport efficiency. Therefore, the network SBM model is suitable for more stringent decision making.

\section{Conclusions}

This study evaluated the transport efficiency of coastal ferry operators by employing undesirable safety-related outputs, which previous studies have thus far not examined. To this end, this study designed a three-stage network SBM model that delineated the production stages of coastal ferry operators as transport service generation (SG), transport service execution (SE), and transport value creation (TC). "Fleet size," "Service frequency," and "Route distance" were selected as input variables for the efficiency analysis. In addition, "Transport capacity" was selected as an intermediate produced in the SG stage and included in the SE stage, and "Passenger-km" as an intermediate produced in the SE stage and included in the TC stage. "Transport sales" and "Safety defects records (SDR)" were selected as output variables. Here, SDR refers to the undesirable outputs considered in this study. It was defined as the sum of accident records (AR) due to human errors/technical faults and detention records of ship (DR) according to the legal safety inspection.

Transport efficiency was evaluated by applying the three-stage network SBM model designed in this study to 23 coastal ferry operators that continuously conducted business from 2015 to 2018. In addition, the general SBM model, which did not consider the internal linking activities of SG, SE, and TC stages, was employed to enable a comparison with the evaluated transport efficiency scores. As a result of applying the three-stage network SBM model, one DMU was indicated as efficient, which scored 1.000 in transport efficiency. The average transport efficiency score of the 23 DMUs evaluated was 0.459. Regarding divisional efficiency in SG, SE, and TC, the fewest DMUs were efficient in the SG stage. This indicates that the coastal ferry transport business has the characteristics of a public transportation service; thus, there is excessive input of fleet size and service frequency to provide consistent transport services. Furthermore, the average transport efficiency score in the general SBM model was 0.753 , and 12 DMUs were efficient, scoring 1.000 in transport efficiency. The transport efficiency scores were higher in the general SBM model than the three-stage network SBM model, and the number of efficient DMUs was also 12 times greater. This highlights the limitation of overestimated transport efficiency when applying the general SBM model, which does not consider the internal linking process of transport service production.

The correlation analysis between overall efficiency and the efficiency scores of each production stage in the three-stage network SBM model showed that overall efficiency had the highest correlation with the efficiency score in the TC stage (correlation coefficient: $0.960, p<0.05$ ). This indicates that the overall efficiency scores of coastal ferry operators are determined by output efficiency reflecting the negative values of undesirable safety-related outputs rather than input efficiency. This study confirmed that by using the three-stage network model, the transport performance of coastal ferry operators could be evaluated in a more balanced way in terms of service quality without leaning toward whether economic service is provided. Finally, conclusion has been drawn that it is advantageous to apply the three-stage network SBM model in this study if it is required to establish more distinctive benchmarking strategy for ferry transport service to enhance the service reliability.

This study is significant in that it not only analyzed the efficiency of coastal ferry transportation more accurately by using the network SBM model but also considered safety management records for overall efficiency evaluation from a sustainable management perspective. Coastal ferry operators require a high level of safety management activities to provide reliable transport service to their passengers. Traffic volume can change sensitively with the occurrence of a marine accident [60]. When recognizing the safety of ferry as a factor to cause demands on the potential production, the level of safety from a ferry operator is inherent in the current performance of transportation from coastal ferry 
operator. As seen in the Sewol ferry disaster (2014), safety has become a management item that can ensure coastal ferry operators' competitive advantage in transport service and determine the outcome of their business. However, safety management activities can constrain the productivity by incurring higher transportation costs [70]. For coastal ferry operators, it would be a realistic management strategy to use available resources efficiently to maximize passenger transport and minimize safety defects during ferry operations. Therefore, measurement of transport efficiency considering safety factors in the field of coastal ferry service is important. This allows monitoring to maintain an appropriate level of safety relative to the transportation performance.

This study is limited for not being able to suggest the results of analysis on the dynamic efficiency in the use of time-series data due to availability and accessibility of safety-related data. To overcome this limitation, follow-up research will be conducted to design a dynamic network DEA model suitable for evaluating coastal ferry transport efficiency.

Author Contributions: Conceptualization, H.K. and J.K.; methodology, H.K. and J.K.; software, H.K.; validation, H.K.; formal analysis, J.K.; investigation, J.K.; resources, H.K. and J.K.; data curation, J.K.; writing —original draft preparation, J.K.; writing—review and editing, H.K.; visualization, J.K.; supervision, H.K.; project administration, H.K.; funding acquisition, H.K. All authors have read and agreed to the published version of the manuscript.

Funding: This work was supported by the National Research Foundation of Korea (NRF) grant funded by the Korea government (MSIT) (No. 2019R1F1A1059037).

Acknowledgments: The authors are grateful to the editor and reviewers for their careful and valuable suggestions.

Conflicts of Interest: The authors declare no conflict of interest.

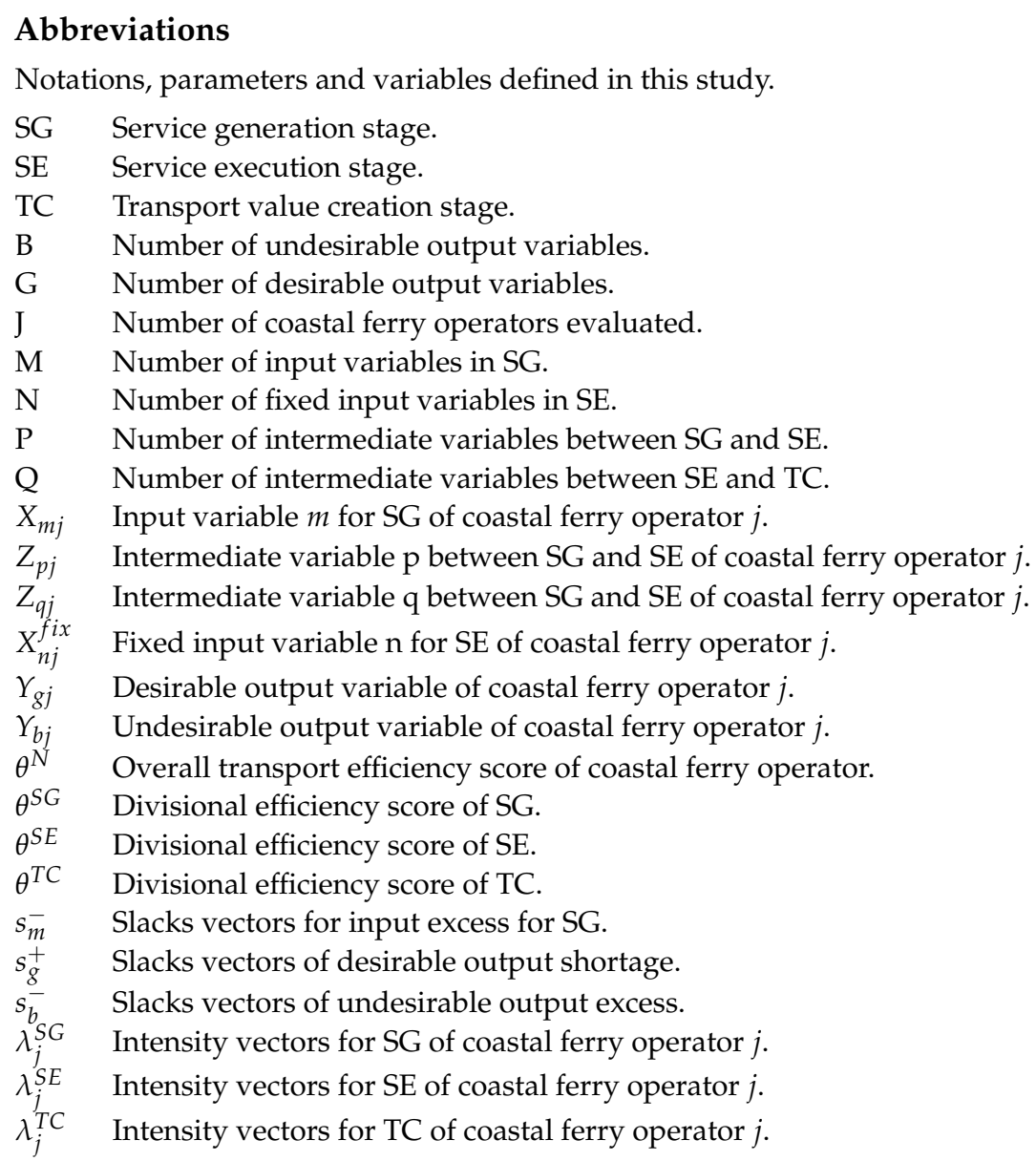




\section{References}

1. Korea Shipping Association (KSA). Status of Coastal Passenger Transportation Services in $2020 . \quad$ Available online: http:/ / www.theksa.or.kr/site/main/board/sub05_08_01_04/81407?cp=1\&sortOrder=BA_REGDATE\&sortDirection=DESC\& listType=list\&bcId=sub05_08_01_04\&baNotice=false\&baCommSelec=false\&baOpenDay=false\&baUse=true (accessed on 5 March 2021).

2. Baird, A. A Scottish east coast European ferry service: Review of the issues. J. Transp. Geogr. 1997, 5, 291-302. [CrossRef]

3. Baird, A.J. Comparing the efficiency of public and private ferry services on the Pentland Firth between mainland Scotland and the Orkney Islands. Res. Transp. Bus. Manag. 2012, 4, 79-89. [CrossRef]

4. Bergantino, A.S.; Bolis, S. Monetary values of transport service attributes: Land versus maritime ro-ro transport. An application using adaptive stated preferences. Marit. Policy Manag. 2008, 35, 159-174. [CrossRef]

5. Tzannatos, E.S. Technical reliability of the Greek coastal passenger fleet. Mar. Policy 2005, 29, 85-92. [CrossRef]

6. Ministry of Oceans and Fisheries. Marine Transportation Act (Act No.15011, 31 October 2017). Available online: http: / / www.law.go.kr/LSW/eng/engLsSc.do?menuId=2\T1 \textsectionion=lawNm\&query=\%ED $\% 95 \% B 4 \% E C \% 9 A \%$ $\mathrm{B} 4 \% \mathrm{~EB} \% \mathrm{~B} \% 95 \& \mathrm{x}=0 \& \mathrm{y}=0 \#$ liBgcolor12 (accessed on 5 March 2021).

7. (MOF) The Ministry of Oceans and Fisheries. Implementation Plan for Maritime Safety in 2020. Available online: https: / / www.mof.go.kr/article/view.do?articleKey=31887\&searchCategory=\%ED $\% 95 \% B 4 \% E C \% 82 \% A C \% E C \% 95 \% 88 \%$ EC $\%$ A0 $\% 84 \% E C \% A 0 \% 95 \% E C \% B 1 \% 85 \&$ searchSelect=title\&searchValue=\%ED $\% 95 \% B 4 \% E C \% 82 \% A C \% E C \% 95 \% 88 \% E C \% A 0$ $\% 84 \% \mathrm{EC} \% 8 \mathrm{~B} \% 9 \mathrm{C} \% \mathrm{ED} \% 96 \% 89 \% \mathrm{EA} \% \mathrm{B3} \% 84 \% \mathrm{ED} \% 9 \mathrm{~A} \% 8 \mathrm{D} \&$ boardKey=22\&menuKey=1013\&currentPageNo=1 (accessed on 5 March 2021).

8. Barak, S.; Dahooei, J.H. A novel hybrid fuzzy DEA-Fuzzy MADM method for airlines safety evaluation. J. Air Transp. Manag. 2018, 73, 134-149. [CrossRef]

9. Chen, C.-M.; Du, J.; Huo, J.; Zhu, J. Undesirable factors in integer-valued DEA: Evaluating the operational efficiencies of city bus systems considering safety records. Decis. Support Syst. 2012, 54, 330-335. [CrossRef]

10. Cui, Q.; Li, Y. Evaluating energy efficiency for airlines: An application of VFB-DEA. J. Air Transp. Manag. 2015, 44, 34-41. [CrossRef]

11. Djordjević, B.; Krmac, E.; Mlinarić, T.J. Non-radial DEA model: A new approach to evaluation of safety at railway level crossings. Saf. Sci. 2018, 103, 234-246. [CrossRef]

12. Egilmez, G.; McAvoy, D. Benchmarking road safety of U.S. states: A DEA-based Malmquist productivity index approach. Accid. Anal. Prev. 2013, 53, 55-64. [CrossRef]

13. Han, J.S.; Kim, H.R.; Go, S.Y. Evaluation of efficiency in the Seoul's arterial bus routes considering undesirable outputs. J. Korean Soc. Transport. 2010, 28, 43-54.

14. Pal, D.; Mitra, S.K. An application of the directional distance function with the number of accidents as an undesirable output to measure the technical efficiency of state road transport in India. Transp. Res. Part A Policy Pract. 2016, 93, 1-12. [CrossRef]

15. Roets, B.; Verschelde, M.; Christiaens, J. Multi-output efficiency and operational safety: An analysis of railway traffic control centre performance. Eur. J. Oper. Res. 2018, 271, 224-237. [CrossRef]

16. Stolzer, A.J.; Friend, M.A.; Truong, D.; Tuccio, W.A.; Aguiar, M. Measuring and evaluating safety management system effectiveness using Data Envelopment Analysis. Saf. Sci. 2018, 104, 55-69. [CrossRef]

17. Friman, M.; Lättman, K.; Olsson, L.E. Public Transport Quality, Safety, and Perceived Accessibility. Sustainability 2020, 12, 3563. [CrossRef]

18. Nocera, S. The key role of quality assessment in public transport policy. Traffic Eng. Control 2011, 52, 394-398.

19. Nocera, S. An operational approach for the quality evaluation in public transport services. Ing. Ferrov. 2010, 65, 363-383.

20. Charnes, A.; Cooper, W.W.; Rhodes, E. Measuring the efficiency of decision making units. Eur. J. Oper. Res. 1978, 2, 429-444. [CrossRef]

21. Banker, R.D.; Charnes, A.; Cooper, W.W. Some Models for Estimating Technical and Scale Inefficiencies in Data Envelopment Analysis. Manag. Sci. 1984, 30, 1078-1092. [CrossRef]

22. Tone, K. A slacks-based measure of efficiency in data envelopment analysis. Eur. J. Oper. Res. 2001, 130, 498-509. [CrossRef]

23. Tone, K. Dealing with Undesirable Outputs in DEA: A Slacks-Based Measure (SBM) Approach; GRIPS Research Report Series; I-2003-0005; 2003. Available online: https:/ / www.researchgate.net/profile/Kaoru-Tone/publication/284047010_Dealing_with_ undesirable_outputs_in_DEA_a_Slacks-Based_Measure_SBM_approach/links/5cca60444585156cd7c1b264/Dealing-withundesirable-outputs-in-DEA-a-Slacks-Based-Measure-SBM-approach.pdf?origin=publication_detail (accessed on 27 May 2021).

24. Tone, K.; Tsutsui, M. Applying an Efficiency Measure of Desirable and Undesirable Outputs in DEA to U.S. Electric Utilities. J. Cent. Cathedra 2011, 4, 236-249. [CrossRef]

25. Tone, K.; Tsutsui, M. Network DEA: A slacks-based measure approach. Eur. J. Oper. Res. 2009, 197, 243-252. [CrossRef]

26. Li, Y.; Shi, X.; Emrouznejad, A.; Liang, L. Environmental performance evaluation of Chinese industrial systems: A network SBM approach. J. Oper. Res. Soc. 2018, 69, 825-839. [CrossRef]

27. Färe, R. Measuring Farrell efficiency for a firm with intermediate inputs. Acad. Econ. Pap. 1991, 19, 329-340.

28. Färe, R.; Grosskopf, S. Network DEA. Socio-Econ. Plan. Sci. 2000, 34, 35-49. [CrossRef]

29. Mahmoudabadi, M.Z.; Azar, A.; Emrouznejad, A. A novel multilevel network slacks-based measure with an application in electric utility companies. Energy 2018, 158, 1120-1129. [CrossRef]

30. Zhu, J. Airlines Performance via Two-Stage Network DEA Approach. J. Cent. Cathedra 2011, 4, 260-269. [CrossRef] 
31. Lozano, S.; Gutierrez, E. A slacks-based network DEA efficiency analysis of European airlines. Transp. Plan. Technol. 2014, 37, 623-637. [CrossRef]

32. Zhang, Q.; Koutmos, D.; Chen, K.; Zhu, J. Using Operational and Stock Analytics to Measure Airline Performance: A Network DEA Approach. Decis. Sci. 2019. [CrossRef]

33. Lozano, S.; Gutierrez, E.; Moreno, P. Network DEA approach to airports performance assessment considering undesirable outputs Appl. Math. Model. 2013, 37, 1665-1676. [CrossRef]

34. Chen, C.; Yan, H. Network DEA model for supply chain performance evaluation. Eur. J. Oper. Res. 2011, 213, 147-155. [CrossRef]

35. Momeni, E.; Azadi, M.; Saen, R.F. Measuring the efficiency of third party reverse logistics provider in supply chain by multi objective additive network DEA model. Int. J. Shipp. Transp. Logist. 2015, 7, 21. [CrossRef]

36. Omrani, H.; Keshavarz, M. A performance evaluation model for supply chain of shipping company in Iran: An application of the relational network DEA. Marit. Policy Manag. 2016, 43, 121-135. [CrossRef]

37. Kahi, V.S.; Yousefi, S.; Shabanpour, H.; Saen, R.F. How to evaluate sustainability of supply chains? A dynamic network DEA approach. Ind. Manag. Data Syst. 2017, 117, 1866-1889. [CrossRef]

38. Wanke, P.F. Physical infrastructure and shipment consolidation efficiency drivers in Brazilian ports: A two-stage network-DEA approach. Transp. Policy 2013, 29, 145-153. [CrossRef]

39. Yu, M.-M.; Lin, E.T. Efficiency and effectiveness in railway performance using a multi-activity network DEA model. Omega 2008, 36, 1005-1017. [CrossRef]

40. Hahn, J.-S.; Kim, D.-K.; Kim, H.-C.; Lee, C. Efficiency analysis on bus companies in Seoul city using a network DEA model. KSCE J. Civ. Eng. 2013, 17, 1480-1488. [CrossRef]

41. Shirazi, F.; Mohammadi, E. Efficiency evaluating and improvement by using the network SBM-DEA model with undesirable output: A case study of Iranian airlines. IJDEA 2019, 7, 47-64.

42. Fukuyama, H.; Weber, W.L. A slacks-based inefficiency measure for a two-stage system with bad outputs. Omega 2010, 38, 398-409. [CrossRef]

43. Huang, J.; Chen, J.; Yin, Z. A Network DEA Model with Super Efficiency and Undesirable Outputs: An Application to Bank Efficiency in China. Math. Probl. Eng. 2014, 2014, 793192. [CrossRef]

44. Lozano, S. Alternative SBM Model for Network DEA. Comput. Ind. Eng. 2015, 82, 33-40. [CrossRef]

45. Liu, Y.; Wang, K. Energy efficiency of China's industry sector: An adjusted network DEA (data envelopment analysis)-based decomposition analysis. Energy 2015, 93, 1328-1337. [CrossRef]

46. Førsund, F.R. A comparison of parametric and non-parametric efficiency measures: The case of Norwegian ferries. J. Prod. Anal. 1992, 3, 25-43. [CrossRef]

47. Bang, H.-S.; Kang, H.-W.; Martin, J.; Woo, S.-H. The impact of operational and strategic management on liner shipping efficiency: A two-stage DEA approach. Marit. Policy Manag. 2012, 39, 653-672. [CrossRef]

48. Chao, S.-L.; Yu, M.-M.; Hsieh, W.-F. Evaluating the efficiency of major container shipping companies: A framework of dynamic network DEA with shared inputs. Transp. Res. Part A Policy Pract. 2018, 117, 44-57. [CrossRef]

49. Chung, C.C.; Hwang, C.C. analysis on vessel registration and operational performance of bulk-shipping firms. Proc. East. Asia Soc. Transport. Stud. 2005, 5, 631-646.

50. Gong, X.; Wu, X.; Luo, M. Company performance and environmental efficiency: A case study for shipping enterprises. Transp. Policy 2019, 82, 96-106. [CrossRef]

51. Gutierrez, E.; Lozano, S.; Furió, S. Evaluating efficiency of international container shipping lines: A bootstrap DEA approach. Marit. Econ. Logist. 2014, 16, 55-71. [CrossRef]

52. Huang, W.H.; Chao, S.L.; Chang, C.C. Assessment of differences in efficiency across strategic groups in the container shipping context: A data envelopment analysis. Int. J. Shipp. Transp. Logist. 2017, 9, 651-672. [CrossRef]

53. Lin, W.C.; Liu, C.F.; Chu, C.W. Performance efficiency evaluation of the Taiwan's shipping industry: An application of data envelopment analysis. Proc. East. Asia Soc. Transport. Stud. 2005, 5, 467-476.

54. Panayides, P.M.; Lambertides, N.; Savva, C.S. The relative efficiency of shipping companies. Transp. Res. Part E Logist. Transp. Rev. 2011, 47, 681-694. [CrossRef]

55. Chang, M.H. A study on the management efficiency of coastal passenger routes in Korea. Korean Logist. Rev. 2010, $20,217-242$.

56. Jo, G.S.; Yeo, G. A Study on the Operational Efficiency of Coastal Passenger Route using a DEA and Malmquist Index. Korean J. Logist. 2013, 21, 67-84. [CrossRef]

57. Caves, D.W.; Christensen, L.R.; Diewert, W.E. The Economic Theory of Index Numbers and the Measurement of Input, Output, and Productivity. Econometrica 1982, 50, 1393. [CrossRef]

58. Yu, M.-M.; Chen, L.-H.; Hsiao, B. A performance-based subsidy allocation of ferry transportation: A data envelopment approach. Transp. Policy 2018, 68, 13-19. [CrossRef]

59. Du, J.; Cook, W.D.; Liang, L.; Zhu, J. Fixed cost and resource allocation based on DEA cross-efficiency. Eur. J. Oper. Res. 2014, 235, 206-214. [CrossRef]

60. Park, S.H.; Pham, T.Y.; Yeo, G.T. The Impact of Ferry Disasters on Operational Efficiency of the South Korean Coastal Ferry Industry: A DEA-Window Analysis. Asian J. Shipp. Logist. 2018, 34, 248-255. [CrossRef]

61. Charnes, A.; Clark, C.T.; Cooper, W.W.; Golany, B. A developmental study of data envelopment analysis in measuring the efficiency of maintenance units in the U.S. air forces. Ann. Oper. Res. 1984, 2, 95-112. [CrossRef] 
62. Pham, T.; Lee, G.; Kim, H. Toward Sustainable Ferry Routes in Korea: Analysis of Operational Efficiency Considering Passenger Mobility Burdens. Sustainability 2020, 12, 8819. [CrossRef]

63. Park, S.H.; Yeo, G.T. Study On ferry business efficiency analysis considering undesirable variable. J. Shipp. Logist. 2020, 36, 1-18.

64. Chang, Y.-T.; Lee, S.; Park, H.K. Efficiency analysis of major cruise lines. Tour. Manag. 2017, 58, 78-88. [CrossRef]

65. Kim, J.; Lee, G.; Kim, H. Analysis of Operational Efficiency Considering Safety Factors as an Undesirable Output for Coastal Ferry Operators in Korea. J. Mar. Sci. Eng. 2020, 8, 367. [CrossRef]

66. Boussofiane, A.; Dyson, R.; Thanassoulis, E. Applied data envelopment analysis. Eur. J. Oper. Res. 1991, 52, 1-15. [CrossRef]

67. Dyson, R.; Allen, R.; Camanho, A.; Podinovski, V.; Sarrico, C.; Shale, E. Pitfalls and protocols in DEA. Eur. J. Oper. Res. 2001, 132, 245-259. [CrossRef]

68. Tsai, W.-H.; Lee, H.-L.; Yang, C.-H.; Huang, C.-C. Input-Output Analysis for Sustainability by Using DEA Method: A Comparison Study between European and Asian Countries. Sustainability 2016, 8, 1230. [CrossRef]

69. Yeh, L.T. Comparative study of various methods for treating zero undesirable outputs in data envelopment analysis. In Proceedings of the ISER 135th International Conference, Saint Petersburg, Russia, 9-10 July 2018.

70. Ma, Y.; Zhao, Q.; Xi, M. Decision-makings in safety investment: An opportunity cost perspective. Saf. Sci. 2016, 83, 31-39. [CrossRef] 